\title{
Prácticas políticas estudiantiles en la Universidad Nacional de Córdoba. Un análisis a través de la figura de los centros de estudiantes
}

\author{
Student political practices in Córdoba National University. \\ An analysis through the figure of student center
}

Marco Antonio Hernández Falcón ${ }^{1}$

Fecha de recepción: 6 de mayo de 2020

Fecha de aceptación: 3 de julio de 2020 


\section{Resumen}

El contenido del artículo inicia con la identificación de una crisis inédita globalizada, signada por aspectos como la desigualdad, la exclusión y la injusticia social; desde donde se despliega un cuestionamiento de lo institucional, en el que el aspecto político cobra centralidad. Partiendo de la institución educativa, y particularmente del aporte de la universidad latinoamericana, la investigación se propuso un análisis de las prácticas políticas estudiantiles a través de la figura de los centros de estudiantes en las áreas de humanidades y ciencias sociales de la Universidad Nacional de Córdoba. El proceder metodológico, de enfoque cualitativo, con un alcance comprensivo-interpretativo, y empleando un método compuesto básicamente por entrevistas semiestructuradas, resalta en los resultados la tensión y la configuración entre espacios de organización y participación estudiantil, ante un dispositivo de neutralización del aspecto político de la formación universitaria pública.

Palabras clave: prácticas políticas estudiantiles, organización y participación estudiantil, universidad pública latinoamericana.

\section{Abstract}

The article's content starts with an identification of an unprecedented globalized crisis, marked by aspects such as inequality, exclusion, and social injustice; from where it unfolds a questioning of the institutional, in which the political aspect gains centrality. Starting from the educational institution, and particularly of the Latin American university's contribution, the research has proposed an analysis of the student political practices through the figure "student centers" (humanities and social sciences areas) of the Córdoba National University. The methodological procedure, with a qualitative approach, and with a method basically composed by semi-structured interviews, stands out in the results the tension and settings between spaces for organization and student participation, in the face of a neutralization device of the political aspect of public university education.

Keywords: student political practices, organization and student participation, Latin American public university. 


\section{Introducción}

$\mathrm{L}$ a crisis socio-ambiental inédita actual contiene el grave deterioro de las condiciones de vida en un segmento muy amplio, mayoritario, de la población del planeta. Santos $(2003,2005)$ sostiene que la modernidad occidental (estructurada en torno al capitalismo, al colonialismo y al patriarcado) se articula en función de dos grandes principios sobre los cuales se organiza una jerarquización social: el sistema de desigualdad y el sistema de exclusión. El mismo autor relaciona el sistema de desigualdad con las condiciones económicas y políticas, y la exclusión con aspectos socioculturales. En los hechos, ambas se entretejen y las personas afectadas por ambas se ven privadas parcial o totalmente de un ejercicio efectivo de su ciudadanía.

En América Latina, heredera y sujeta histórica de la colonización, de diversos regímenes políticos autoritarios y dictatoriales, la desigualdad y la exclusión son particularmente relevantes. El efecto de estas condiciones se ha intensificado en grupos poblacionales como el de los jóvenes, quienes viven "en un escenario latinoamericano signado por la vulnerabilidad y la exclusión social" (Oraisón, 2010, p. 75). Estos enfrentan problemáticas vinculadas con diversos tipos de violencia y la ausencia de un estado que garantice efectivamente sus derechos. Viven una erosión del tejido y de los vínculos sociales, con la consecuente pérdida de seguridad e identidad que éstos proveen. Aunado a ello padecen muy frecuentemente la falta de acceso a un trabajo digno como vía de inclusión social. $^{2}$

Esta juventud se encuentra muy distante de una clase política instalada en el poder institucional, dentro de un supuesto régimen democrático representativo, que resalta en su discurso técnico y macroeconómico una gran riqueza -incluyendo aquella que alude a los recursos naturales- que no se distribuye de manera equitativa entre la gran mayoría de sus, claramente, no representados. Su vida transcurre generalmente dentro de un contexto político, socioeconómico y cultural que obstaculiza e inhibe su involucramiento en las relevantes decisiones que van marcando la pauta de la dinámica social, y que podrían estar orientadas a promover una desconcentración y redistribución de un poder político y económico que, en términos generales, los ha mantenido al margen. Resulta paradójico que interactuemos dentro de un marco normativo democrático, que coexiste con una creciente e indignante injusticia social. Un número muy significativo de ellos, que componen el grueso de la pirámide poblacional, no manifiestan confianza en las instituciones del estado y no están presentes en los nimios -prácticamente inexistentes- espacios institucionales de debate, deliberación pública y toma de decisiones de impacto colectivo.

El escenario antes mencionado cuestiona severamente el funcionamiento de las principales instituciones, surgiendo y desarrollándose, en respuesta al mismo, muy diversas demandas orientadas a la transformación social. En la investigación que dio pie al presente artículo, nos enfocamos en la institución educativa, y más particularmente en la universitaria pública, en tanto espacio que [aún] puede propiciar el cambio cultural y en donde se disputa en diferentes frentes el sentido de

2- La Organización Internacional del Trabajo (OIT) estimó, para el año 2018, una tasa de desempleo para México de 3.7\%; y un porcentaje del $27 \%$ de "empleo vulnerable"; esto es, de personas que no tienen acceso a seguridad social y perciben ingresos muy bajos. Lo anterior se encuentra descrito en el informe "Perspectivas sociales y del empleo en el mundo-tendencias 2018". 
la dinámica social; ya sea hacia el mantenimiento y adaptación a las condiciones actuales, ya sea para cuestionar críticamente el orden establecido para interpelarlo, agrietarlo y promover su transformación. Desde la cuna del reformismo latinoamericano, se analizan ciertas prácticas políticas estudiantiles, a través de los centros de estudiantes, en relación con su referente contextual a través de ejes de análisis como lo son su aspecto socio-histórico e ideológico, las demandas y su influencia en los arreglos institucionales, sus mecanismos de organización, sus desafíos cruciales, y su relación con otras organizaciones.

\section{Contexto socio-histórico y educativo institucional de la investigación}

Las características que definen a la institución universitaria, consolidada durante el devenir de los siglos, responden a un momento socio-histórico. Bell (1994) lo ejemplifica refiriéndose a una institución propia de la sociedad postindustrial, o de la sociedad del conocimiento. Asimismo, la universidad responde a las particularidades regionales que condicionan la manera en que operan y son concebidas. Albornoz (2018) nos recuerda que el surgimiento de las primeras universidades se debió a la asociación que, en torno a la defensa de sus intereses, formaron maestros y estudiantes; conformando un gremio que no podía crear conocimiento, dado que esa autoridad únicamente pertenecía a la iglesia. A partir de ello, las instituciones universitarias irán definiendo objetivos como, por ejemplo, el de liderar la generación de conocimiento científicotecnológico, o la formación de profesionales que pudiesen contribuir a la comprensión y/o a la solución de problemáticas sociales.

Las condiciones socio-históricas han ido reconfigurado las diversas concepciones y sentidos del quehacer universitario. Para el caso occidental, la concepción de la universidad como la casa de la ciencia (un antecedente relevante de ella es el modelo universitario de Wilhelm von Humboldt, plasmado en la Universidad de Berlín) se originó en el contexto de una crisis política que desembocó en una reorganización del Estado germano (Albornoz 2018, basado en Bonvecchio, 1991):

el proyecto de von Humboldt para la educación, en general, y las universidades, en particular, les asignaba la función de investigar dando impulso a la ciencia pura y, al tiempo, una más trascendente: la de regenerar el Estado. Esta universidad resolvía dialécticamente la paradoja de conducir hacia la interioridad del encuentro con la ciencia pura y hacia el Estado, como sostén y garante. A partir de entonces, de la mano del iluminismo, la universidad comenzó a ocupar un lugar de mayor centralidad y el Estado asumió el control directo y la organización del aparato universitario. (Albornoz, 2018, p. 20)

Por su parte, en la universidad napoleónica, de un perfil más burocrático y profesionalista, se integraban aquella concepción ilustrada que surgió de la Revolución Francesa, con la función política del Estado en tanto garante total y exclusivo de la educación universitaria. 


\subsection{La universidad latinoamericana, una configuración y aportación específica}

En el caso de la región latinoamericana, ubicándonos ahora en el hito histórico de la conquista, Arocena (2018, basado en Müller, 1996) señala que dicho acontecimiento instaló su propia concepción universitaria, la versión de una "universidad de la fe" (p. 35); ésta, según Tünnerman (1991), inspirada en las universidades de Salamanca y Alcalá de Henares. Dicha institución jugaría de manera relevante un papel ideológico-educativo acorde a la dominación extranjera, se trataba de una universidad colonial que no alojaba espacios institucionales de discusión de ideas diversas, ni de investigación científica. Sin embargo, el mismo Arocena advierte: "Pero en los intersticios de la ortodoxia dominante en los claustros, no pocos estudiantes americanos accedieron a las obras de la Ilustración” (2018, p. 35).

Posteriormente, la independencia implicaría una redefinición del sentido institucional, orientándose hacia la formación de élites intelectuales de las repúblicas emergentes, constituyendo un nuevo modelo dominante, el de una universidad republicana. Esta se centraría en la formación de profesionales dentro de una periferia geopolítica signada por un proceso de industrialización; que daba pie a un proyecto educativo en el que se desarrolló cierta concepción del conocimiento científico, y que tendría lugar preponderantemente en una región de Europa y en los Estados Unidos.

Durante el devenir socio-histórico, a partir de las particulares condiciones de desigualdad imperantes en la América Latina del siglo XX, se iría forjando un movimiento con un ideal de universidad socialmente comprometida, de la que se desplegó una concepción protagónica, la universidad de la reforma (Arocena, 2018, p. 37), en la que se impulsaba la formación de sujetos políticos de orientación transformativa.

Siguiendo la línea de tiempo hasta ahora trazada, y de la mano de lo que se conoce actualmente como globalización, se enfatiza la entrada a escena de los mercados y los corporativos transnacionales orientados a la competitividad, al comercio internacional, y al poder del capital financiero. Con ello, cobra mayor fuerza una veta de mercantilización de los servicios educativos, dejando sentir su influencia en acuerdos internacionales y en las políticas de los gobiernos nacionales. Paralelamente, organismos internacionales como la UNESCO (2009) advertirían los riesgos que esta tendencia conlleva; si bien la competencia podría contribuir a impulsar la excelencia en el ámbito académico, también podría contribuir de cierta manera a un deterioro de la comunidad, la misión y algunos valores académicos tradicionales.

La concepción del quehacer universitario se juega entonces en la manera en que se interrelaciona con su entorno histórico, social, económico, político y cultural; lo que configura una tendencia institucional dominante puesta siempre en tensión con otras que orbitan -más o menos visibles- en torno a ella. En el mismo sentido, la historia latinoamericana ha aportado una especificidad a la concepción del quehacer universitario. Especificidad que se ha ido configurando en torno a problemáticas como la desigualdad, exclusión, injusticia social, y autoritarismo. Arocena (2018), en torno a la concepción de la universidad de la reforma a la que se hizo referencia anteriormente, expone:

La propuesta inspiradora puede ser caracterizada por la aspiración a democratizar la universidad a través de la participación directa del estudiantado en el cogobierno universitario, para que la universidad contribuyera a su vez al desarrollo de procesos democratizadores de la 
sociedad en su conjunto, mediante la práctica interconectada de las funciones de enseñanza, investigación y extensión. Esto implicaba promover la gratuidad y la ampliación del acceso a la institución; asimismo, comprometerla con la búsqueda de soluciones a los problemas colectivos, prioritariamente a los que impactan a los sectores sociales más desfavorecidos. (p. 37)

El mismo autor identifica claramente una brecha significativa entre lo ideal y lo que efectivamente se lograría, pero también una contribución e incidencia relevantes en la realidad a través de luchas sociales democratizadoras y comprometidas con la justicia social. Esta manera de concebir a la universidad sería "un significativo referente de la tradición fundamental de la educación superior de la región, y una experiencia sin real parangón a escala internacional. Su surgimiento puede ser visto como una revolución académica en el mundo de la periferia" (Arocena, p. 37). Desde esta concepción se produjeron demandas diversas relativas a la vida universitaria, como aquellas vinculadas a la autonomía, al cogobierno, la libertad de cátedra, los cargos docentes a través de concursos, y el vínculo entre docencia e investigación; trascendiendo hacia el aspecto histórico, político y socioeconómico de la región.

A partir de este antecedente contextual, nos vamos trasladando hacia la situación actual; toda vez expuestos los cuestionamientos que orientaron la investigación, así como su ruta metodológica. Partiendo entonces del legado de la universidad de la reforma, nos dirigimos selectivamente a aquella bajo el embate del dictado neoliberal, a través de los centros de estudiantes de la Universidad Nacional de Córdoba (UNC), cuna del reformismo latinoamericano.

\subsection{Los cuestionamientos que orientaron la investigación}

La pregunta central que orientó la investigación fue ¿cómo se configura la relación entre las prácticas políticas estudiantiles desplegadas por los centros de estudiantes de las áreas de humanidades y ciencias sociales de la UNC, y el contexto socio-histórico y educativo institucional que las enmarca? En torno a ella orbitaron cuestionamientos como los siguientes:

¿Cómo se han sostenido históricamente los centros de estudiantes, cómo se han institucionalizado y, al mismo tiempo, han seguido presumiblemente cerca de las demandas o las agendas estudiantiles?

¿Quiénes, cómo, y ante qué fueron formados? ¿Cómo han sido atravesados por diversos hitos socio históricos e institucionales? ¿De qué han sido portadores? ¿Con qué actores sociales han hecho sus principales alianzas y con quiénes sus principales antagonismos?

¿Cuáles son las dificultades más relevantes que enfrentan actualmente y cómo las están asumiendo? ¿Qué lugar ocupan los centros de estudiantes dentro del concierto de los movimientos estudiantiles, sociales y populares en Argentina?

\section{La ruta metodológica}

Estamos frente a una investigación cualitativa de alcance comprensivo-interpretativo, con un componente crítico; la ruta metodológica se orientó hacia un escenario conformado por ciertas prácticas políticas estudiantiles en relación con las condiciones socio-históricas y educativas institucionales que las 
enmarcan y permean. En cuanto a la temporalidad, una noción transversal. La atención se focalizó sobre los centros de estudiantes (espacios de formación política que nuclean ciertos intereses gremiales), de las áreas de humanidades y ciencias sociales de la UNC, buscando identificar la perspectiva de los sujetos y otorgar un papel preponderante a sus expresiones.

El aspecto epistemológico de la investigación se ubicó en un lugar cercano al estructuralismo (en el que autores como Marx, en la vertiente del materialismo dialéctico, son un antecedente referencial). Cabe aclarar que dicha cercanía posibilitó un énfasis en el supuesto de ciertos niveles de autonomía o de cierta capacidad de agencia -tanto a nivel personal como colectivo- ante la tendencia determinante de las estructuras. Así pues, se concibió una relación dialéctica entre colectividad-sujeto y las estructuras que dan forma a la dinámica social. Nutrido de miradas como la de Vygotsky (1985), Freire (1969, 2005); así como de la pedagogía crítica (Giroux, 1993; Apple, 2002; McLaren 2011), se resalta la vinculación y el compromiso de sectores importantes de la comunidad universitaria con la construcción de una sociedad más incluyente y justa a través de la atención en una formación universitaria pública y latinoamericana no sólo en el sentido de un buen profesional, sino también en el de un sujeto político; o dicho de otra manera, de quien puede ejercer de manera autónoma, crítica, activa y democrática su ciudadanía.

En el análisis de la configuración entre los sujetos y su contexto institucional referente se recurrió también al trabajo desarrollado, desde la filosofía política, por autores como Rancière (1996), Laclau y Mouffe (2004), Mouffe (2016), y Castoriadis (2007); para quienes de alguna manera todo orden establecido está limitado por aquello que es incapaz de institucionalizar; desde estos límites a los que antecede lo instituyente, o lo social (y lo educativo), se generan pugnas que eventualmente conllevarían a agrietar la estructura, a interpelar lo hegemónico.

Desde el entendido de que la manera en que se entreteje la información que a través de cada técnica se obtiene es lo que configura el método, las técnicas utilizadas para la aproximación a las categorías fueron el análisis de contenido documental, la observación y principalmente las entrevistas semiestructuradas. Estas últimas fueron conformadas por un esquema general y flexible de preguntas en cuanto a orden, contenido y formulación de las mismas.

Para efecto de las entrevistas y las observaciones, fue posible estar en la sede (UNC) tanto durante el mes de septiembre de 2016, como durante el mes de noviembre de 2019; período durante el cual se conversó con 27 interlocutores, principalmente estudiantes de los centros. La delimitación de la muestra poblacional se estableció a partir de los criterios de saturación, consistencia en las respuestas y de la disponibilidad de los recursos de investigación. El recorte en torno a las áreas de humanidades y de ciencias sociales obedeció a criterios como el de que el interés de investigación -según los propios interlocutores- se manifiesta con mayor intensidad, explicitación y trascendencia "extramuros"; o por el de ser uno de los campos más sensibles, a la vez que soslayados, ante proyectos socio-educativos tendientes a la privatización y a la mercantilización.

Las observaciones se llevaron a cabo durante 32 días en diferentes espacios de la sede. En cuanto al análisis documental, se recurrió a referentes de índole internacional (como aquellos elaborados por organismos como la UNESCO o la Conferencia Regional de Educación Superior), leyes y reglamentos nacionales en materia de educación, normas institucionales de la UNC (como las que exponen el perfil de la UNC; o aquellos referentes a su vida estudiantil, al ejercicio de su ciudadanía, a sus derechos; así como relativos a la reforma universitaria, a la misión institucional, y al gobierno universitario), publica- 
ciones gremiales sindicales (como es el caso del Gremio de Docentes e Investigadores Universitarios de Córdoba, ADIUC), y algunos escritos estudiantiles (expresados en gacetas o periódicos).

\subsection{Ejes y sentido del proceso general de análisis}

Las categorías empleadas fueron flexibles en el encuentro y en el tratamiento con las especificidades del referente empírico, sin que ello implicara perder la posibilidad de llevar a cabo un análisis integral entretejiéndolas y entramándolas críticamente. En ese sentido, los ejes centrales se constituyeron a partir de los siguientes temas:

1) Etapas socio-históricas que atraviesan a la organización estudiantil, y al contexto institucional que las enmarca; 2) Influencias ideológicas; 3) Agenda y demandas; 4) Relación con la política e incidencia en el proyecto educativo institucional, en los procesos de enseñanza-aprendizaje y en el currículum en general; 5) Mecanismos de organización; 6) Vinculación con organizaciones (estudiantiles) y movimientos sociales; 7) Logros, dificultades, y desafíos centrales; 8) Relación con los docentes (particularmente con el gremio sindical).

El proceso general de análisis se conformó a partir del registro y sistematización de eventos significativos que, entre otras cosas, fueron posibilitando la definición de las categorías, éstas se interrelacionaron con un conjunto de supuestos iniciales y con lo acontecido durante la vinculación con el referente empírico, orientándose hacia la aprehensión de un orden integral que funcionó como una herramienta para la inteligibilidad y la comprensión. Se elaboró una trama en la que todos estos elementos se encuentran imbricados entre sí, afectándose mutuamente.

\section{Resultados, análisis y discusión. De lo institucional a los actores sociales, una relación socio-histórica de tensión}

En 1918 el movimiento estudiantil reformista publicaba en la gaceta universitaria de la UNC el Manifiesto Liminar ${ }^{3}$. El contenido de este manifiesto significó un drástico e insalvable desacuerdo estudiantil ante un ejercicio monárquico y monástico del poder'; representó una inquietud insumisa orientada a la democratización de la institución universitaria. Este hito histórico, contemporáneo a las luchas sociales de la época, se expandió en años sucesivos a toda América Latina, se proyectó al Mayo Francés de 1968, $\mathrm{y}$ a posteriores luchas universitarias del mundo entero.

Este movimiento que promovió cambios estructurales en las universidades públicas argentinas extendió su convocatoria a la juventud universitaria latinoamericana consignando que, si en el nombre del orden se nos quiere seguir burlando y embruteciendo, proclamamos bien alto el derecho sagrado a la insurrección. Al menos desde aquel año, las y los estudiantes de la UNC se pronunciaban ya por la autonomía universitaria, la gratuidad, la laicidad, la libertad de cátedra, la unidad obrero-estudiantil, el relevo de las estructuras, el cambio en los objetivos de las universidades, el empleo de nuevas estrategias de

3- Manifiesto de la Federación Universitaria de Córdoba, publicado en 1918.

4- Se utilizan palabras inclinadas para indicar una mención textual atribuida a las y los estudiantes reformistas. 
enseñanza-aprendizaje, la libertad de expresión y de pensamiento, el compromiso con la realidad social, y la participación en el gobierno universitario; así como por la defensa de una educación pública.

La UNC se ha ido constituyendo desde entonces como un referente latinoamericano --histórico y contemporáneo- de un complejo proceso de democratización socio-institucional. Proceso en el que se encuentran presentes en todo momento conflictos y tensiones generados por diversos actores sociales; y en el que las prácticas políticas de los estudiantes han jugado un papel fundamental. Características institucionales como el acceso irrestricto, la gratuidad, y el cogobierno ${ }^{5}$ no hubiesen podido instalarse y operar sin la activa participación estudiantil. Esta participación se relaciona con diversos momentos históricos que, sin lugar a dudas, permearon la dinámica universitaria e hicieron un énfasis en su aspecto sociopolítico, inseparable de una agenda educativa-académica, que trascendió los muros y la frontera nacional para vincularse con movimientos sociales reformistas de diversos países latinoamericanos.

Esta institución destaca entonces por el reconocimiento de un conjunto de derechos estudiantiles, entre los que se encuentran aquellos de tipo político. Asimismo, explicita un discurso en torno a la defensa de una educación pública y concibe a ésta como un bien social, resistiendo los embates contemporáneos de concepciones educativas ligadas al lucro y a la mercantilización que provienen tanto del exterior como del interior de la misma.

La universidad cuna del reformismo latinoamericano impulsó la posición iberoamericana en la Conferencia Mundial de Educación de 1998 (París), en la que se pugnó por establecer al conocimiento como un bien social ${ }^{6}$. Asimismo, ubica al Estado como el responsable de su financiamiento y como el que tiene que preservar la autonomía universitaria.

La UNC recientemente fue sede de la Conferencia Regional de Educación Superior 2018, hecho que coincidió con el centenario de la reforma universitaria. En ella, se identificó un desencuentro, que se manifiesta desde comienzos del presente siglo, entre las políticas neoliberales y una concepción de la educación (de universidades públicas regionales) como un bien público social y orientado por el eje constituido por los Derechos Humanos. Estas políticas neoliberales surgen desde organismos internacionales como la Organización Mundial del Comercio y el Banco Mundial, desde donde se concibe a la educación como una mercancía. Concepción que comulga con un proceso de privatización de la misma y que resulta también una manera de controlarla políticamente.

Este centro universitario lleva a cabo diversos eventos conmemorativos que hacen eco a las voces de diversos sectores sociales que tienen presente momentos históricos significativos, ejemplo de ello es el denominado: "1976-2016 memoria, verdad y justicia”, evento a partir de la conmemoración de los 40 años del golpe de estado que originó la última dictadura cívico-militar en Argentina. Es pues, un home-

5- En términos generales, cualquier aspirante a ingresar a la UNC (y a cualquier universidad pública argentina) en calidad de estudiante, tiene garantizado el acceso; es decir, no se topará con una experiencia de rechazo como resultado de la aplicación de evaluaciones orientadas a separar a los aspirantes en dos grupos: los aceptados y los no aceptados. La carrera de medicina es probablemente la única excepción, ya que deben rendir un examen de ingreso cuya calificación mínima debe ser 7 . Toda vez matriculado, el estudiante no desembolsa recursos para pagar aranceles, colegiaturas o cuotas de recuperación. Es relativamente frecuente que en la UNC estudien jóvenes procedentes de diversos países latinoamericanos, a quienes esto les resulta más conveniente al menos en términos económicos. Finalmente, el gobierno de la universidad incluye a una representación estudiantil que participa activamente en las decisiones de mayor impacto y trascendencia para la comunidad universitaria.

6- Dentro de su información institucional, la UNC advierte que la Organización Mundial del Comercio (OMC) ha puesto sobre la mesa la posibilidad de incorporar a la educación superior dentro de los servicios regulados por el Acuerdo General de Comercio de Servicios (AGCS, o GATS en inglés). 
naje a las víctimas de lo que un significativo número de ciudadanos consideran un episodio histórico de terrorismo de Estado.

La misión institucional declara orientarse por los valores nucleares de la sociedad y del pueblo al que pertenece. Declara en la misma que su fin es la educación plena de la persona humana y, derivado de ello, tanto la formación profesional como técnica, así como la investigación y el desarrollo de la cultura. Aunado a lo anterior, la integración comunitaria dentro de un clima de autonomía y convivencia democrática. La misión también implica la formación de un universitario socialmente comprometido, así como a darle difusión al saber entre todos los estratos de la población mediante programas de extensionismo. En el discurso escrito, la extensión universitaria prioriza la dignificación del hombre y la formación de una sólida conciencia democrática.

Por otro lado, dentro del ámbito de gobierno, la Asamblea Universitaria, el Consejo Superior, los Consejos Directivos de las Facultades y los Consejos Consultivos de las Escuelas son los órganos centrales ${ }^{7}$. El espacio nuclear en donde se toman las decisiones de mayor impacto a toda la comunidad universitaria es el Consejo Superior, conformado por representantes de los cuatro claustros (estudiantes, docentes, no-docentes, y egresados), los decanos o decanas de cada facultad, y la rectoría de la UNC. Las y los estudiantes emiten su voto para elegir a los representantes del claustro en el Consejo Superior y en los Consejos Directivos (de esta manera renuevan a sus representantes en el Consejo Superior y en los Consejos Directivos de cada una de las facultades). Eligen también, de la misma manera, a las autoridades de los centros de estudiantes. Las decisiones conjuntas tienen que ver, por ejemplo, con aprobar y reformar planes de estudio, designar a los docentes de cada asignatura, aprobar importantes inversiones en infraestructura, realizar declaraciones institucionales sobre diversas temáticas de agenda pública, elegir al decano/a de las facultades, y elegir al Rector.

En ese sentido, recuperando el tema de los derechos que asisten a las y los estudiantes, éstos se dividen en tres tipos: académicos, sociales, y políticos. Dentro de los sociales están aquellos relacionados con actividades culturales que promuevan la formación integral y ciudadana de los mismos. En el caso de los políticos, los facultan para ser partícipes de las decisiones de impacto colectivo dentro de un sistema institucional de cogobierno. Estos derechos contemplan la posibilidad de organizarse en agrupaciones y centros de estudiantes y, a la vez, el derecho de elegir y ser elegido como representante para los órganos que conforman dicho cogobierno ${ }^{8}$. El discurso escrito institucional indica que este sistema de gobierno compartido es acatado por todas las universidades públicas del país, reconociéndolo como un logro estudiantil.

En ese sentido, y dirigiéndonos hacia los centros de estudiantes, cabe hacer mención de que la UNC posee una defensoría de la comunidad universitaria, que fue creada en 1997 por el Consejo Superior como una instancia de mediación en la defensa de los principios y derechos universitarios. Asimismo, se dispone de la Secretaría de Asuntos Estudiantiles (SAE), instancia orientada a acompañar el ingreso, el avance y la culminación de las trayectorias estudiantiles. Dice promover que los mismos conozcan sus

\footnotetext{
7- En cada uno de estos órganos de gobierno, los jóvenes cuentan con una representación estudiantil. Los mismos deciden y debaten en torno a la agenda de la vida institucional como la elección de autoridades que incluyen a los directores, a los decanos y al rector. Aunado a lo anterior, cada facultad cuenta con un centro de estudiantes, organización autónoma de representación de los intereses estudiantiles. Los quince centros de estudiantes de la UNC componen la Federación Universitaria de Córdoba (FUC).

8- Información disponible en la página oficial de la UNC: https://www.unc.edu.ar/
} 
derechos, los compartan y difundan; que exijan que sean respetados. También que sean protagonistas y que, incluso, se organicen no sólo para hacerlos valer, sino también para conquistar otros nuevos. Todas las facultades cuentan con una secretaría, que a su vez integran una general a nivel central. Gaby ${ }^{9}$, quien trabaja en la Secretaría de Asuntos Estudiantiles, en la Facultad de Ciencias de la Comunicación, expuso que el objetivo es facilitar el tránsito estudiantil y la culminación de los estudios; para lo cual cuentan con recursos -entre otros- como becas, eventos de acogida, culturales, y orientación vocacional.

\subsection{Los centros de estudiantes: orígenes, adscripciones y características de un espacio gremial de formación política}

Las organizaciones estudiantiles ligadas a la dinámica universitaria en la UNC, y en general en todas las universidades públicas de la Argentina, son numerosas y muy variadas. La Federación Universitaria de Córdoba (FUC) es el órgano máximo que aglutina a los estudiantes de la UNC, y la Federación Universitaria de Argentina (FAC) la conducente a nivel nacional. En el caso de los centros, a partir de lo expresado por los interlocutores, pueden estar ligados -o no- a partidos políticos u a otras organizaciones sociales de nivel local, nacional o internacional; lo que implica ideologías que genéricamente podrían vincularse con el comunismo, socialismo, anarquismo, capitalismo; o con un poco más de detalle, al marxismo (en vertientes como el leninismo o trotskismo), o al feminismo. Se distinguen también adscripciones más "internas" como el peronismo (en sus diferentes vertientes), el kirchnerismo, el macrismo, etc. Durante la vinculación con el referente empírico, se fueron identificando cuatro posturas: populismo/progresismo, izquierda "radical", derecha, y los independientes. De manera un tanto contingente, se dio una mayor aproximación a la popular/progresista, atribuimos esto -entre otras cosas- a una presencia más extendida dada la potencia de identificación con el proyecto político en el poder durante los años comprendidos entre 2003 y 2015 (y que regresaría a partir de diciembre de 2019) en el campo disciplinar elegido. Cabe mencionar que, aunque las dos primeras posturas se ubican a la "izquierda", para la segunda, los primeros no promueven una transformación a nivel estructural.

Mathías, del centro de estudiantes adscrito al área de ciencias de la comunicación, mencionó que éstos datan de muchos años atrás, suponía que germinaron en torno al movimiento reformista del 18 y que eventualmente se consiguió que fueran respaldados por una Ley General de Educación que observa la obligatoriedad de que los secundarios (en México serían las secundarias y las preparatorias o bachilleratos) y las universidades cuenten con ellos. Algunas estudiantes del centro de filosofía y humanidades coincidieron en que éstos provienen de las principales demandas de la reforma del 18, y más específicamente, de la línea constituida por el cogobierno.

Según las fuentes consultadas, la FUC proviene de la reforma del 18 y sus antecedentes, desarrollándose sobre todo dentro de la vertiente del cogobierno, en donde se fue configurando una plataforma política básica. Se constituye como un espacio gremial que politiza e incentiva la participación estudiantil,

9- El nombre original ha sido modificado para acentuar la consideración a las y los interlocutores que accedieron a participar en la investigación. En lo sucesivo, cuando se cite textualmente lo que algún participante mencionó, se utilizarán las palabras en la modalidad de inclinación. 
su concepción del sujeto educativo implica tanto un evidente aspecto pedagógico como uno político, y por su naturaleza se orienta y pugna por la defensa y el ejercicio de sus derechos.

En el curso de la historia de las organizaciones estudiantiles, estas se crean y se terminan cumpliendo plazos temporales muy variables, lo mismo puede suceder en torno a ciertos ajustes o adecuaciones a sus programas y agendas. Brignardello (2007) indica que en Argentina existen agrupaciones estudiantiles desde antes del siglo XX, al menos en la Universidad de Buenas Aires (UBA). En su Facultad de Ciencias Exactas se formó la asociación atlética "La Línea Recta", claro que con funciones muy distintas a las de un movimiento o centro actual. Esta asociación atlética unida a otra de carácter cultural es la que dio origen al centro de estudiantes de ciencias exactas; posteriormente sería el centro de estudiantes de ingeniería "La Línea Recta" (esto alrededor del año 1894).

En complemento de lo anterior, para la misma autora: "La existencia de las agrupaciones estudiantiles [como es la de los centros de estudiantes] gira sobre dos constantes que alternan su importancia, la expresión política y la labor gremial. Cumplen por tanto funciones análogas al gremio y al partido político" (Brignardello, 2007, p. 21). Dentro del devenir histórico, algunas expresiones han sido muy politizadas, mientras que otras, en respuesta, se han pretendido apolíticas; y la capacidad de convocatoria de ellas puede ser muy variable. Estas organizaciones han centrado su atención en temas preponderantemente académicos-escolares, y en otros casos los han vinculado con temas estructurales socio-educativos.

Siguiendo a esta autora que estudió el origen de las organizaciones estudiantiles, la Federación Universitaria de Buenos Aires (FUBA) se constituiría en 1908, mientras que en Córdoba los movimientos estudiantiles entran a escena sobre todo partiendo de la reforma del 18 (así como la FUC). Basándome en la misma fuente, es pertinente indicar que en el gobierno de Frondizi (1958-1962), a través de pugnas en donde fue relevante la participación estudiantil, se aprueba la ley que establece un nuevo régimen universitario, pues se asienta un gobierno tripartito que admite la representación estudiantil. Un hito posterior y en sentido contrario lo constituiría la intervención a las universidades nacionales, hecho suscitado al llegar al poder, en el año 1966, el gobierno del general Onganía (una dictadura militar). En dicha intervención, diversos centros de estudiantes fueron clausurados; pero también, y en respuesta a la misma, se formaron múltiples organizaciones estudiantiles. Es decir, así como una movilización social puede alentar la activación de una agrupación, una opresión puede también estimular el desarrollo de ella.

\subsection{Hitos socio-históricos e influencias ideológicas regionales: la reforma, la dictadura, la transición democrática y la tensión entre neoliberalismo y movimientos populares}

Desde una corriente histórica e ideológica que atraviesa hitos como la ilustración y las revoluciones francesa, rusa y mexicana, autores como Arocena (2018) identifican una veta histórica latinoamericana que implica a la reforma universitaria, en tanto un proyecto de democratización de la universidad para que ésta contribuyera a la democratización de la sociedad, y por tanto a cierto tipo de desarrollo ${ }^{10}$. Se

10- El autor se refiere a una concepción de desarrollo utilizada por Sen (2000), es decir, un desarrollo en términos éticos, un desarrollo humano sustentable, que concibe a las personas como agentes sociales. 
destaca que en la década de los 60s y 70s, según Suasnabar (2011), en la región se consolida la idea de una universidad latinoamericana, de alta relevancia política. Período al que le seguiría el advenimiento de dictaduras, particularmente en el cono sur, lo que implicaría un punto de inflexión y neutralización de los proyectos políticos de transformación social:

Son los años del exilio donde se desarrollará un proceso de revisión crítica de aquellas experiencias políticas que derivará en una reflexión teórica y conceptual, cuya expresión más visible será el desplazamiento del problema de la revolución hacia la cuestión de la democracia. (p. 140)

Posteriormente se fueron posicionando, preponderantemente a partir de reformas estructurales que se han promovido desde los noventas, políticas que lograron resignificar el sentido de las universidades. Éstas han sido relativamente homogéneas en los distintos países de la región, aunque con sus respuestas regionales particulares, "volviéndolas cada vez más instituciones terciarias para el entrenamiento profesional y menos universidades en el sentido del saber para transformar, hacer ciencia y socializarla a favor de una identidad ciudadana crítica" (Mollis, 2011, p. 50).

Si bien es cierto que, ante la caída de la dictadura en Argentina, la transición política se orientó hacia la instauración y el desarrollo de una democracia representativa -en términos de un discurso que proclamaba un gobierno del pueblo y para el pueblo-, ésta fue siendo objeto de intensas presiones provenientes de poderes como el militar y el económico. En el primer caso, para tornar inviable una procuración de justicia ante las más graves violaciones a derechos humanos fundamentales; en el segundo caso, para la implantación, desarrollo y funcionamiento de un modelo neoliberal que concibe un desarrollo humano individual-social en términos preponderantemente económicos, y que prometía un gran y sostenido crecimiento -en ese sentido- a la población.

Estas condiciones pudieron ser contribuyentes de un desencanto social contemporáneo en torno a la democracia. Borón (2009) aborda el tema de las democracias latinoamericanas posteriores al ocaso de las dictaduras: "democracias que explotan, excluyen, empobrecen y que marginan a las clases y estratos populares mientras contribuyen al desenfrenado enriquecimiento de las minorías adineradas." (pp. 11,12). El mismo autor cuestiona incluso que se le llame democracia a regímenes que caracterizan -más bien- a las plutocracias u oligarquías.

Una parte relevante de la clase política se evidenció comprometida ante los embates supuestamente irrefrenables de la globalización económica (por ejemplo, ante la posibilidad de una crisis económica generada por la ausencia de condiciones atractivas para los inversionistas) y aceptó condiciones convenientes para el poder económico transnacional. Lo anterior incidió definitivamente en rupturas y crisis de representación política que propiciaron la emergencia de movilizaciones y nuevas organizaciones sociales que demandaban ser tomadas en cuenta, el acceso a decisiones de impacto colectivo y el respeto de sus derechos ciudadanos. De manera simultánea, se incubó y se desarrolló una apatía hacia lo político y lo público en amplios sectores poblacionales.

Durante los años noventa, la UNC sufrió un destacado embate, originado desde el poder económico neoliberal, en el sentido fundamental de su discurso institucional ${ }^{11}$. Embate que, a decir de algunos 
interlocutores, permeó la estructura organizacional institucional. Según el contenido de algunos diálogos sostenidos con algunos profesores de esta institución, la UNC pudo más o menos resistir este impacto soportada en pilares como el construido a partir de una historia e identidad que le otorgan una tradición institucional íntimamente vinculada con amplios y diversos sectores sociales regionales, y por el construido a partir de una organización conformada por un nutrido grupo de profesores y, sobre todo, de estudiantes universitarios. Sin embargo -advierten- las señales de un nuevo y más poderoso embate (de la misma procedencia), son claras ${ }^{12}$. En este último, la desactivación política parece ser un objetivo central.

Para Bonetto (2015), luego de la crisis del neoliberalismo en la región latinoamericana, emergieron ciertas condiciones que permitieron imaginar la posibilidad de una política democrática movilizada, colectiva y militante. Este proceso representó una alternativa ante la gobernanza de corte neoliberal. La autora considera a "la década kirchnerista" como promotora de transformaciones que constituyeron una ruptura con el pasado y una construcción de alternativas a través de una propuesta de ampliación de derechos y equidad social (la construcción de una agenda postliberal) constantemente cuestionada por el poder económico. En este contexto, habría surgido una intensa participación de colectivos y organizaciones políticas juveniles -antes apartados de la política- que han abonado a una transición de una ciudadanía individual a una popular, y han interpelado la idea de la globalización neoliberal como el único destino posible para la sociedad.

En el abordaje comprensivo de dicha ruptura nos ayudaron perspectivas analíticas que distinguen entre un orden social establecido, o institucional (que implica mecanismos orientados a la anulación del conflicto), y una posible organización desde lo que queda fuera o al borde, que puede irrumpir, cuestionar y reconfigurar ese orden a través de la constitución de sujetos políticos. Éstos pudiesen aspirar al advenimiento de una nueva hegemonía a partir de significantes particulares, que se generalizan logrando constituirse, a través del poder, en una objetividad social; generando una naturalización de cierta dinámica social en detrimento de otras alternativas (Rancière, 1996; Schmitt, 1998; Mouffe, 1999; Laclau y Mouffe, 2004; y Castoriadis, 2007). Lo instituyente, o lo social, siempre excede los límites de todo intento de constituir la sociedad en términos absolutos. En ese sentido, una formación vinculada a la constitución de sujetos políticos estaría orientada a des-sedimentar o desnaturalizar el orden institucional dominante, visibilizando su carácter socio-histórico y político.

Desde la organización y participación política popular, se institucionalizaron demandas populares socioeducativas que concebirían a la educación como un bien público y un derecho humano, que debe ser garantizada por el Estado (artículo 2do de la Ley de Educación Nacional). Se ubica a la misma como una prioridad nacional para, entre otras cosas, construir una sociedad más justa, intensificar el ejercicio de una ciudadanía democrática, y promover el desarrollo económico-social de la nación.

El artículo séptimo del mismo referente normativo, indica que el Estado debe ser el garante del acceso de la ciudadanía a la información y al conocimiento en tanto instrumentos centrales de la participación

nentes marchan de manera orquestada y sí, por el contrario, referirse a ella en términos de un espacio en donde se disputan y desencuentran diversas visiones y perspectivas; me refiero aquí a un discurso que, entre otros pronunciamientos, propone y defiende una educación pública en tanto un bien común que debe contribuir a la disputa y desarrollo de una sociedad más inclusiva y justa.

12- Comentarios expresados durante el mes de septiembre del año 2016. 
en un proceso de desarrollo, con crecimiento de la economía y con la prevalencia de justicia social. El décimo indica que el Estado no suscribirá acuerdos bilaterales o multilaterales de comercio libre que impliquen una concepción de la educación como un servicio lucrativo, o bien promuevan una mercantilización de la educación pública. Por su parte, el artículo 11 explicita los objetivos de la política educativa institucional; el inciso "c" establece que se debe formar una ciudadanía comprometida con la ética y la democracia, tanto como en la participación y en el respeto a los derechos fundamentales. En tanto que el inciso "e" se orienta a garantizar la inclusión educativa empleando estrategias pedagógicas y de asignación de recursos dando prioridad a los sectores más desprotegidos de la sociedad; mientras que el inciso "i”, afianzar la participación democrática de maestros, familias y estudiantes en las instituciones educativas de todos los niveles.

Ubicándonos en el momento actual: es decir, dentro de las tensiones entre el neoliberalismo y la organización popular que lo cuestiona, se expone lo directamente vinculado a la sede. Evocando dichos antecedentes, múltiples expresiones pictóricas, artísticas y políticas que ocupan las paredes y los muros circundantes al centro de estudiantes en la Facultad de Ciencias de la Comunicación, éstos fueron el preámbulo del contacto con algunos de los interlocutores, como Alex, miembro de la organización estudiantil "La Bisagra". A partir de los encuentros con los estudiantes de esta organización, dio la impresión de que en términos generales los universitarios que la componen habían tenido acceso a experiencias socioculturales de una formación política identificada con algunos aspectos centrales del Peronismo ${ }^{13} \mathrm{y}$ del Kirchnerismo ${ }^{14}$.

Alex (durante el mes de septiembre de 2016) reconoció que la formación política se vive con intensidad dentro del ambiente universitario Cordobés ${ }^{15}$, particularmente en el ámbito de las ciencias sociales y las humanidades. Consideró que, aproximadamente, el 10\% de los estudiantes de la UNC son también militantes de alguna organización política, y que este 10\% se extiende hasta el 50 o $60 \%$ cuando se trata del porcentaje de participación estudiantil en procesos electorales. En términos generales, los interlocutores no pusieron en duda cierto nivel de representación gremial, no exenta de críticas dada la dinámica democrática representativa, y el desplazamiento que lo institucional ejerce sobre otras perspectivas disidentes ${ }^{16}$.

Para David, la actividad de los centros de estudiantes está atravesada por las disciplinas académicas. Así, la intensidad de la dinámica política que caracteriza al campo de las ciencias sociales y humanidades, disminuye en campos como el de la administración ${ }^{17}$. La cuestión disciplinar juega un papel relevante

13- Movimiento político argentino surgido a mediados de la década de los 40, con un pronunciado énfasis en el tema de la justicia social y popular.

14- Movimiento político de orientación peronista fundado en el año 2003, con una importante participación de quienes en su momento constituyeron - precisamente- la "juventud peronista". El movimiento destaca una agenda popular compuesta por una oposición ante el neoliberalismo, un fortalecimiento del estado, una integración latinoamericana y una férrea defensa a los derechos humanos.

15- Al respecto y a manera de ejemplo, Alex refiere las constantes discusiones que se llevan a cabo en el Consejo Superior protagonizadas por profesores y alumnos, debido a que algunos intereses de ambos grupos no son siempre convergentes.

16- Complementando lo mencionado, durante la relación con el referente empírico se identifican en general niveles relevantes de "apatía" en procesos de elecciones de representantes estudiantiles y otras prácticas políticas, expresión que se aborda en otros apartados del texto; sin embargo, no identificamos una postura consistente en torno a que los centros no gozaran de cierta representatividad gremial, reconociendo también que las preguntas empleadas para recopilar la información no estaban dirigidas a dicho tema.

17- Por poner un ejemplo, cuando las organizaciones estudiantiles del campo disciplinar de administración compiten para ganar una elección y ocupar espacios de poder, no llevan a cabo debates entre ellas, tal como sucede con los de las ciencias 
[en esto hubo mucha coincidencia entre los estudiantes], Luis declaró abiertamente que, en el caso de comunicación social, el centro busca una politización del estudiante...serán futuros periodistas dijo, y reconoció que en otras disciplinas dicha politización no resulta tan relevante.

Alex desconocía desde cuando tienen presencia los centros de estudiantes ${ }^{18}$ en la UNC, pero sí sabía que datan de muchos años atrás y que seguramente se formaron en respuesta a una intensa necesidad de defender intereses gremiales ante una concentración del poder en otros actores sociales. Afirmó que uno de los principales objetivos es promover que los estudiantes no abandonen sus estudios. A partir de lo que él mismo, y otros interlocutores expresaron, se identificaron concretamente los siguientes eventos históricos como significativos en tanto la influencia de los mismos sobre la dinámica universitaria y, más específicamente, sobre el desarrollo de una cultura política estudiantil:

1. El peronismo, movimiento que irrumpe a mediados de los cuarenta, implicó en una de sus vertientes un significativo proceso de politización estudiantil y de la dinámica universitaria, a través de un proceso caracterizado por el trayecto de una universidad de élites hacia una universidad del pueblo.

2. Los movimientos revolucionarios latinoamericanos en los años sesenta y setenta, como el cubano y chileno, que impulsaron y posicionaron ideologías políticas que permearon a la UNC.

3. El Cordobazo (1969): Alex dijo con certeza que durante la rebelión popular que caracterizó al Cordobazo ya había una intensa actividad desde los centros de estudiantes cordobeses (particularmente desde aquellos ubicados en la UNC).

4. El kirchnerismo: movimiento político de orientación peronista, al que se hizo referencia con anterioridad, que comprende un período que va del año 2003 al 2015.

\subsection{Los centros de estudiantes en guardia: resistencia ante el dictado neoliberal}

Las y los universitarios que conforman los centros de estudiantes llevan a cabo reuniones semanales donde se construye y se discute la agenda estudiantil que pretenden posicionar en los espacios institucionales de conversación, confrontación, deliberación pública y toma de decisiones. Estas reuniones, en articulación con la organización de los mismos centros, cuentan con un presidente y un secretario; en ellas, se va definiendo la postura en torno a los temas de dicha agenda a través de diversas comisiones como de género, de derechos humanos, o de integración latinoamericana.

Las organizaciones estudiantiles suelen tener estatutos y reglamentos que indican su forma de organización, y suelen recurrir a asambleas o congresos en donde se discuten alternativas para enfrentar determinadas problemáticas o desafíos. Cuentan con delegados en los consejos de las facultades, y con

sociales y las humanidades.

18- Los centros de estudiantes en Córdoba operan desde el nivel secundario, los estudiantes de 13 o 14 años pueden votar por sus representantes y quienes están próximos a egresar pueden participar para ocupar la dirección y, por tanto, gestionar uno de estos centros. 
consejeros o conciliarios en el Consejo Superior de la Universidad o en comisiones especiales que tratan algún asunto en particular. Desde la perspectiva de las y los interlocutores, el sentido central de la organización estudiantil en cuestión es la defensa y la ampliación de los derechos estudiantiles; así como el apoyo a la permanencia, la inclusión y la defensa de la educación pública.

Iván refirió que algunas organizaciones estudiantiles se articulan, son acuerpadas, o son gestionadas por estructuras políticas más amplias (como un partido político, por ejemplo) que determinan cierta verticalidad en la manera de organizarse; se refirió a la suya como una organización en donde impera una dinámica horizontal con una importante vinculación con organizaciones políticas tanto del interior de la UNC como al exterior de la misma. Por su parte, Luisa reconoció que el conflicto, en los encuentros de organización que llevan a cabo los estudiantes, está presente en todo momento y que no todas las decisiones pueden ser tomadas de manera horizontal.

Los centros de estudiantes gestionan una agenda estudiantil que, claro está, posiciona en el debate público temas relacionados estrictamente con asuntos académicos internos, pero que también incluye temas sociopolíticos que trascienden los muros de la UNC; ejemplo de ello es -según Alfredo- el esperado intento de recorte presupuestal a la educación superior que promovería el presidente Mauricio Macri (con el aval de organismos económicos internacionales). Este último representó para cierto sector socioeducativo un interés orientado a la mercantilización y al control político de la educación.

Autores como Apple (2002) hacen un énfasis en lo que se advierte como un proceso de mercantilización de la enseñanza disfrazado de reformas educativas que pueden estar adornadas de un discurso seductor, pero que funcionan de manera opuesta al llegar a la realidad de las aulas. Este autor considera que la educación de calidad que abanderan estas reformas implica una "colonización del discurso profesional por parte de modelos empresariales cuya única preocupación no es la calidad, sino la obtención de beneficios" (p. 48). Identifica también un paradigma dominando los proyectos tanto sociales como educativos; paradigma político, económico y cultural al que se refiere como neoliberalismo que, en esencia, es un capitalismo sin ninguna contemplación.

Para Santos (2015), la postura de organismos multilaterales como el Banco Mundial implican una concepción mercantilista de la educación, lo que formaría parte de un dictado neoliberal para la universidad. Apunta que las inversiones globales en educación ascienden a 2 billones de dólares, más del doble de aquellas comprometidas en el mercado mundial del automóvil, lo que representa un atractivo para el capital interesado en nuevos nichos de valorización. Lo anterior ha conllevado a que el tema de la educación superior se posicione en el Acuerdo General sobre Comercio de Servicios, actualmente en negociación en el seno de la Organización Mundial de Comercio.

Ante la pregunta que orientó la investigación, se configuró entonces una relación de tensión y resistencia entre la organización y participación política estudiantil y su entorno socio-histórico e institucional; lo que se dirime en frentes como el currículum, lo que sucede al interior de las aulas, la legislación universitaria, los derechos estudiantiles, y el vínculo estudiante-docente. Esta tensión refleja pugnas de lo superficial a lo estructural dentro de polos constituidos por elementos como lo privado versus lo público, lo vertical versus lo horizontal, lo autoritario-exclusivo versus lo democrático-inclusivo; y lo impuesto desde arriba versus lo posicionado desde abajo.

Carlos, de la Facultad de Filosofía y Humanidades, que identificó dicho centro como el más politizado de la UNC, no sólo coincidió en que actualmente la universidad pública es sujeta de medidas de control 
y desactivación política, apuntó una autocrítica dirigida a los propios centros en el sentido de que les hace falta pisar barrio; esto es, no quedarse en una burbuja academicista en donde lo relevante es demostrar quién es más o menos letrado. La universidad -dijo- tendría que ir al barrio: es pública, es de ellos también. Carlos, al igual que Alex, reconoció la vinculación que estos centros de estudiantes mantienen con organizaciones internas y externas a la UNC; pero también, que es necesario ampliar y profundizar el vínculo con las segundas.

Mathías consideró que hoy día (esto se mencionó durante el mes de noviembre de 2019) la dificultad más grande para los centros es aquella ligada al aspecto económico, pues el abandono de los estudios puede ir de la mano de un joven al que no le alcanza para la comida, el transporte o el material para la escuela. En este sentido, la universidad sigue enfrentando el desafío de ser accesible a un amplio sector juvenil que ni siquiera aspira a ocupar un espacio en ella; es decir, a poco más de 100 años de la reforma, el desafío de vincularse con los sectores sociales más desfavorecidos. Gabriel, adscrito a una de las Secretarías de Asuntos Estudiantiles, coincidió con lo anterior. Por otro lado, una dificultad "interna" a la que se hizo alusión implica las tensiones entre aquellas corrientes negociadoras y aquellas radicalizadas que aparentemente no muestran cierto nivel de flexibilidad que posibilite algunas alianzas estratégicas, $o$ concesiones que puedan ganar algo -que no todo- en lugar de nada.

Mercedes y Facundo (de la organización "Freire", adherida a "Estudiantes al Centro", organización que forma parte de la dirección del centro estudiantil en la Facultad de Filosofía y Humanidades) refirieron una dificultad relevante, central y estructural, vinculada a la lógica neoliberal que propicia, o que produce apatía e individualismo. Expresaron que si bien la militancia, de la mano de la formación académica-disciplinar desgasta; se sostiene soportada en el deseo, el placer, y la interpelación. Luisa, otra participante, refirió que sabía de muchos casos, sobre todo en escuelas secundarias particulares, donde las autoridades presentaban obstáculos para la constitución de un centro de estudiantes.

Para Puiggrós (1996), sosteniendo este proyecto neoliberal, habría una concepción de la educación como una actividad orientada al lucro; siendo así, la formación de ciudadanía ligada a la responsabilidad que el Estado le había conferido a la educación en períodos históricos anteriores es replegada en tanto la preponderancia del aspecto económico.

Desde esa perspectiva, las universidades están respondiendo a una lógica del mercado, actor proyectado desde antecedentes como el consenso de Washington. Para la misma autora, se han logrado ir desplegando las condiciones socio-educativas de producción de un sujeto neoliberal. Ante este dictado contemporáneo, que tiende a neutralizar los espacios de una formación política crítica, autores como Zibechi (2003) identifican que los jóvenes (entre ellos los universitarios), junto con los pueblos originarios y las mujeres, son los principales actores emergentes ligados a movilizaciones sociales y populares capaces de interpelar formas dominantes y autoritarias; es decir, se han posicionado como potenciales agentes de transformación social.

Ante un dispositivo institucional, sostenido por uno subyacente o estructural de cierre o neutralización de espacios formativos que podrían propiciar el desarrollo de herramientas socioculturales vinculadas a la organización y participación política estudiantil, se configura a través de diversos intersticios una relación de tensión, de defensa de lo público, de lo político y de lo democrático, pues ¿cómo propiciar la participación de los jóvenes que tienen acceso a educación superior en los procesos políticos que generan las condiciones de acceso a una vida digna, si no se forman participando activamente de aquellas que se dirimen en los diversos espacios que conforman la vida estudiantil universitaria? 


\subsection{Una experiencia in situ: un hito histórico que revela la correlación de fuerzas a nivel de la sede}

Se consigna una experiencia que muestra la correlación de fuerzas aludidas a nivel de la sede. Durante la tarde del sábado 24 de septiembre de 2016 los tambores irrumpían, cada vez con mayor intensidad, en la explanada que delimita el comedor universitario; al interior del mismo se llevarían a cabo las elecciones estudiantiles para dirigir la FUC. La organización estudiantil La Bisagra iniciaba a pintar de naranja (el color de sus playeras y de sus banderas) un tercio de la explanada al ritmo de una batiente batucada. Acto seguido, la organización Mella ${ }^{19}$ ocupaba gradualmente el centro de la explanada. Por último, la organización Sur completaba la ocupación total de la parte frontal de dicho espacio.

Mientras este acomodo se llevaba a cabo, algunos interlocutores dejaban en claro que, desde el 83 (año al que se refieren como el del regreso o la vuelta a la democracia), la organización Franja Morada había resultado ganadora de todas las elecciones para dirigir la FUC. Aunque las agrupaciones políticas La Bisagra, Mella, y Sur habían disputado históricamente espacios de poder, en esta ocasión y de manera inédita, lograron construir un frente común al que denominaron Agustín Tosco ${ }^{20}$. Por su parte, La Franja Morada se trasladaba y llegaba al área del comedor estudiantil universitario por la parte de atrás, evitando así un encuentro visual y frontal que, según los interlocutores, hubiese tensado el ambiente hasta el punto de un posible enfrentamiento.

No obstante nuestra bien recibida mexicanidad en la comunidad universitaria cordobesa durante el encuentro con el referente empírico, nos fue negado el acceso al comedor, en donde estaba por llevarse a cabo tanto el proceso de emisión como el de conteo de votos. Resentimos la negativa dado que nos estábamos acostumbrando a que las puertas se nos abrieran con relativa facilidad. Un grupo de personas con aspecto un tanto intimidante resguardaban las entradas, no portaban identificación institucional alguna. Uno de los interlocutores comentó "en corto" que estas personas formaban parte del soporte y cobijo que la rectoría proporcionaba a Franja Morada.

Los estudiantes conformantes del frente Agustín Tosco se expresaban vigorosos y alegres, aunque un tanto nerviosos; la impresión que dio es de un nivel significativo de confianza respaldada en un autorreconocimiento de su propia capacidad de organización. Ese día, la historia del poder y la organización política estudiantil podía dar un giro que seguramente incomodaría al Rector de la UNC, y al mismo presidente de Argentina (Macri), dadas las implicaciones en juego.

Finalmente, mientras se escuchaban los cohetes y los tambores, las puertas del comedor universitario se abrieron de par en par, abruptamente atravesadas por un grupo de jóvenes que un tanto eufóricos iniciaban a entonar la canción distintiva del Cordobazo (uno de los hitos regionales mencionado con anterioridad); el frente Agustín Tosco obtuvo mayor número de votos que Franja Morada. Esta última acababa de perder la conducción de la FUC.

19- En alusión a Julio Antonio Mella, periodista y revolucionario cubano asesinado en la ciudad de México, en donde se encontraba exiliado. Durante su estancia en La Habana (Cuba) asumió la presidencia de la Federación Estudiantil Universitaria durante el año 1923, participó activamente en la organización y desarrollo del Primer Congreso Estatal de Estudiantes, del que emana el acuerdo de creación de la Universidad Popular José Martí. Fue también fundador del primer partido marxista-leninista cubano.

20- Dirigente sindical argentino, adherido a los postulados marxistas, que tuvo un rol protagónico durante el Cordobazo. 
Para María, adherida a La Bisagra y presidenta del centro de estudiantes de la Facultad de Ciencias Sociales (de la carrera de Trabajo Social), recuperar la FUC como gremio, como espacio de organización y también de defensa de los derechos estudiantiles y ciudadanos son los principales desafíos por venir.

Aproximadamente 3 años después nos enteraríamos que el Frente Agustín Tosco perdería la conducción de la FUC, un año después de haber ganado las elecciones; sin embargo, actualmente (noviembre de 2019) La Bisagra ocuparía la secretaría general de dicha organización.

\subsection{Los derechos políticos y el cogobierno: un logro medular}

Las y los interlocutores identificaron diversos logros de los centros de estudiantes, Martín los definió como un espacio gremial que tienen por objeto que las y los estudiantes transiten de la mejor manera posible y culminen con su trayectoria universitaria, a tal punto de considerar que si aquellos no existieran, la deserción sería mayor; es decir, entre otras cosas, dijo que se busca propiciar que el estudiante se sienta como en casa, contribuir a generar condiciones de apropiación estudiantil del espacio universitario; esto va desde el tiempo del día que el estudiante pasa en la universidad, como su incidencia en las decisiones fundamentales de la vida universitaria; como por ejemplo, gobierno, docencia, planes de estudio, etc.

Lo anterior implica que los estudiantes pueden incidir en la definición de su trayectoria académica en cuanto a qué materias cursar y con qué docentes hacerlo. Asimismo, cuentan con la opción de un régimen de estudiante-trabajador, que se refiere a un conjunto de facilidades para que un estudiante que tenga un compromiso laboral no tenga, por ello, que renunciar a sus estudios universitarios. En relación con la Secretaría de Asuntos Estudiantiles pueden coincidir, articularse, o bien, tensarse; esto ante las actividades desplegadas, unas desde un espacio gremial, y otras desde uno institucional.

Un logro central, vertebral digamos, de la organización estudiantil, con un claro antecedente reformista, ha sido el cogobierno universitario; condición que reivindica el reconocimiento de los derechos políticos estudiantiles y que mantiene abiertos espacios de participación estudiantil que posibilitan la defensa de sus derechos y la lucha por otros más. A su vez, influye en una formación universitaria que dota de cierta lectura de la realidad, contribuyendo a la constitución de sujetos políticos o agentes sociales.

La pedagogía crítica, desde planteamientos como los de Freire $(1969,2005)$, contribuye al análisis; desde dicha perspectiva teórico-práctica la educación es acción para transformar al mundo. La formación de sujetos políticos e históricos es una constante en el trabajo de este autor, quien señala que el acceso al poder y a la toma de decisiones es fundamental en una auténtica democracia. Para McLaren (2011), son decisivas un conjunto de prácticas orientadas a develar la manera en que las estructuras de poder y privilegio fijan los objetivos educacionales. Mientras que Giroux (1993) ha abogado por dar expresión a un concepto crítico de ciudadanía por medio de una propuesta radical de formación política. Desde su punto de vista, recuperar y apropiarse popularmente de la educación permite propiciar una formación crítica y emancipadora. Propone que los actores educativos legitimen a las escuelas como esferas públicas democráticas; por tanto, como lugares que proporcionan un servicio público esencial para la formación para el desempeño de un papel protagónico en el desarrollo de una sociedad democrática y de una ciudadanía crítica. En las instituciones educativas, en tanto construcciones históricas y culturales, se tendrían que desmontar las relaciones de poder develando su relación con fuerzas estructurales más amplias. 
Destacando el aspecto político-educativo de la relación entre los sujetos y sus contextos, para Castoriadis (2007) la política es una actividad colectiva capaz de ir definiendo las condiciones de vida de las personas y que, entre otras cosas, debe cuestionar a las instituciones existentes en la sociedad. Para él, la democracia representa una afirmación de libertad, así como la posibilidad de crear nuevas y diferentes determinaciones de conformación social. Considera que el vértice de una sociedad autónoma es la participación de los ciudadanos, para lo que la educación (la paideia) es una pieza central. Por tanto, es necesario establecer disposiciones institucionales que faciliten la participación de los ciudadanos o de los miembros de cualquier colectividad -ya sea que se trate de sindicatos, de asociaciones estudiantiles, etcétera- que promuevan la participación del demos. Siendo así, en este caso el estudiante universitario trascendería el ámbito técnico instrumental disciplinar para interesarse activamente en lo que sucede en la sociedad, dado que - se supone- forma parte de una polis democrática. Tendría que contar con una formación que abone a pensar políticamente la realidad en que vive, condición fundamental para la ciudadanía (Castoriadis, 1990).

Cabe hacer mención que Diana, docente con una responsabilidad directiva en el área de Ciencias de la Educación, expresó que, aunque no hay estudios al respecto, sí hay indicios claros de que una organización estudiantil vigorosa contiene la deserción escolar ${ }^{21}$. Asimismo, que los centros de estudiantes, al conformar un espacio de formación política contribuyen, y lo han hecho históricamente, a la constitución de un dispositivo de análisis social de la realidad, de talante transformativo, que se integra con una formación de carácter disciplinar.

\subsection{A medio camino entre lo institucional y los actores sociales: los docentes, un referente estudiantil central}

A medio camino entre el referente normativo institucional y la organización estudiantil, y a partir de la premisa consistente en considerar que las prácticas políticas de los docentes influyen en la dinámica política estudiantil, nos pareció pertinente destacar una breve referencia a la plataforma discursiva del Gremio de los Docentes e Investigadores Universitarios de Córdoba (ADIUC); que a lo largo de su conformación y desarrollo ha pugnado abiertamente por una universidad pública, laica, gratuita, autónoma, democrática, cogobernada, de calidad y productora de conocimiento científico. Para ellos, "La universidad deviene un dispositivo nodal para los procesos de acumulación y por tanto central para las luchas contemporáneas" (2019, p. 3$)^{22}$.

Desde el proceso de construcción de una herramienta política discutida y construida colectivamente, la ADIUC contribuye a un debate social en torno a qué tipo de ciencia y universidad se requiere en el marco de qué tipo de país:

21- En una primera revisión de la literatura al alcance, y en consonancia por lo expresado por la interlocutora, no se encontró ninguna ruta o línea de investigación que formule una correlación entre un proceso de apropiación del espacio público a través de la organización y participación política estudiantil, y la deserción escolar. Una próxima investigación pudiera atender esta interesante ruta.

22- Ésta y la siguiente cita textual son tomadas de los apuntes del Instituto Oscar Varsavsky, del gremio de docentes e investigadores de Córdoba (ADIUC): "Fundamentos teórico-políticos. Una apuesta para revitalizar el debate público acerca de la política científica y académica de nuestra región” (2019). Información disponible en http://adiuc.org.ar/2019/11/28/ fundamentos-politicos-y-conceptuales-del-instituto-oscar-varsavsky/ 
Como trabajadores del conocimiento, necesitamos pensar la universidad de nuevas maneras, quizás al modo de una serie de espacios que se están reconfigurando y dentro de los cuales las instancias gremiales de docentes e investigadores resultan transversales y estratégicas. Y ello, en tanto se ocupan de las condiciones materiales y epistémicas de producción y transmisión del conocimiento, además de brindar un potencial estratégico y político para la constitución de proyectos colectivos de transformación de dichas condiciones. $(2019$, p. 5)

Esta organización gremial considera que el ingreso irrestricto y la masividad de la comunidad universitaria han sido pilares de la educación en el contexto cordobés; se oponen a cualquier intento de privatización o mercantilización de la misma. Asimismo, pugnan por un sistema científico que desarrolle líneas de desarrollo con pensamiento crítico, plural y orientado a la transformación social.

Es decir, el de una ciencia sensible a las necesidades y demandas populares; que propicie activamente una democratización social. Considera relevante la defensa de las conquistas que socialmente se han conseguido en torno a los derechos humanos, así como una profundización de las políticas de verdad, memoria y justicia. Lo anterior se extiende hacia la defensa de los derechos de los trabajadores, hacia un énfasis en el reconocimiento de un pensamiento regional latinoamericano en contraposición a uno impuesto por algunas agencias multilaterales, y hacia la ampliación del presupuesto para ciencia y universidad.

Hay una alusión a la política de la ciencia que, en el marco del pensamiento latinoamericano de la década de los setenta, permitió vislumbrar un potencial revolucionario. Para Rita Laura Segato (s. f.), en los años sesenta y setenta, la universidad era un lugar para la imaginación, una especie de isla democrática”. La misma autora reconoce que ahora la universidad no es más ese lugar, se declara convencida que habría que recuperar algo de ese modelo en tanto que se posicionó a nivel mundial; la universidad pública latinoamericana como el lugar de la imaginación se habría perdido con las dictaduras.

A nivel gremial, estos docentes e investigadores identifican una precarización de la vida universitaria; reclaman un incremento salarial y un mejoramiento de las condiciones laborales, así como una participación en la definición de los criterios utilizados por las instancias de evaluación científica e institucional que actualmente operan ponderando determinados parámetros de eficiencia y productividad.

Para finalizar, en consonancia con las voces estudiantiles, los agremiados y simpatizantes de la ADIUC identificaron que el gobierno actual (el de Mauricio Macri) intenta un [nuevo] embate a la educación superior desde un modelo económico, político y cultural neoliberal; una manera de continuar con aquél que instalaron en los tiempos del terrorismo de estado y que implosionara en el año 2001. Por tanto, enmarcan su acción profesional en la propuesta y construcción de una defensa, así como en la generación de una alternativa política ante ello.

\section{Conclusión (a manera de cierre)}

Conformantes de una especie de bastión del bien público, diversas universidades públicas latinoamericanas portan una historia que invita a rescatar, defender y fortalecer espacios insumisos desde donde pueden configurarse modos alternativos de organización social ante la concentración excluyente y antidemocrática del poder económico y político prevaleciente. Es decir, a reposicio- 
narla en la región como un espacio donde pueda formarse una ciudadanía democrática (fusionada con la formación profesional y científica) basada en una organización y participación política orientada a la inclusión y al compromiso social, en donde el conflicto estará presente en todo momento.

Los movimientos estudiantiles, a través de ciertas prácticas políticas, en este caso la de los centros de estudiantes han pugnado por la presencia de sus demandas en los arreglos institucionales (de otra manera no les hubiesen concedido nada) a lo largo de la historia de la UNC, reconfigurándose ante los diferentes condicionantes socio-históricos. Ejemplo de ello no sólo es el cogobierno, sino también la gratuidad y el acceso irrestricto; y particularmente el ejercicio de sus derechos políticos. Estas expresiones pueden ser alentadas por la irrupción de movilizaciones sociales "externas", ligadas a determinados eventos contextuales, y/o por un recrudecimiento del ejercicio autoritario del poder institucional formal.

Los centros de estudiantes de la UNC, cuna del reformismo latinoamericano, han posibilitado, junto con otros actores sociales, espacios de formación política que propician el desarrollo de herramientas de análisis crítico de la realidad social. Se enfrentan actualmente al deterioro del aspecto económico y, de fondo, a un dispositivo neoliberal que se arraiga y opera en la propia conformación de las subjetividades a través de formas como el individualismo, la apatía, la pretensión de una educación apolítica, y la neutralización de la imaginación de alternativas. Sin embargo, la organización, la participación y la militancia, por muy desgastante que pueda llegar a ser, se soporta [aún] en el deseo, el placer, la interpelación y la indignación.

Una organización nunca eximida del conflicto, de tensiones internas, de crisis de representación, de confrontaciones ideológicas; que ocupa espacios institucionales de poder a través de disputas que desplazan perspectivas disidentes, y que tienden a mantener su perspectiva como la imperante; con el riesgo siempre latente de perder legitimidad en tanto pueden acercarse o alejarse a intereses ligados a la autoridad o al de una organización política en particular. Mientras que, con todo y sus limitantes, coadyuva a contener el abandono escolar en tanto -entre otras cosas- posibilita cierta apropiación estudiantil del espacio público universitario, considerando absolutamente necesario reforzar el tejido y la vinculación con la comunidad, preponderantemente con el sector más vulnerable. Finalmente, una organización desde donde se puede contribuir a la generación de alternativas ante problemáticas sociales de alto impacto vinculadas al neoliberalismo, que sin lugar a dudas se contrapondrá con los intereses de quienes las detentan.

\section{Referencias}

Albornoz, M. (2018). Reformar la universidad en la sociedad del conocimiento. En M. Albornoz y M. Crespo (Comp.), Reformar la universidad. Lecciones de 1918 (pp. 15-32). OEI.

Apple, M. (2002). Educar “como Dios manda”; mercados, niveles, religión y desigualdad. Paidós.

Arocena, R. (2018). A cien años del Manifiesto de Córdoba: orientaciones y perspectivas de una nueva

Reforma Universitaria. En M. Albornoz y M. Crespo (Comp.), Reformar la universidad. Lecciones de 1918 (pp. 33-52). OEI.

Bell, D. (1994). El advenimiento de la sociedad postindustrial. Alianza Editorial.

Bonetto, S. y Martínez, F. (2015) (Comp.). Militancia y juventud. CEA-UNC.

Bonvecchio, C. (1991). El mito de la universidad. Siglo XXI. 
Borón, A. (2009). Notas sobre el fetichismo democrático en América Latina. Espartaco.

Brignardello, L. (2007). Movimientos estudiantiles en Argentina. Dunken.

Castoriadis, C. (2007). La institución imaginaria de la sociedad. Tousquest.

Federación Universitaria de Córdoba. (18 de junio de 1918). Manifiesto Liminar. La Gaceta Universitaria. Recuperado de http://www.unc.edu.ar/sobre-la-unc/manifiesto-liminar

Freire, P. (1969). La educación como práctica de la libertad. Tierra Nueva.

Freire, P. (2005). Pedagogía del oprimido. Siglo XXI.

Giroux, H. (1993). La escuela y la lucha por la ciudadanía. Siglo XXI.

Laclau, E. y Mouffe, C. (2004). Hegemonía y estrategia socialista. Hacia una radicalización de la democracia. FCE.

Ley 26.206 de 2006. Ley de Educación Nacional de Argentina. Ministerio de Educación de la República Argentina. 14 de diciembre de 2006. Recuperado de http://www.inet.edu.ar/index.php/institucional/normativa/ley-de-educacion-nacional/

McLaren, P. (2011). El Che Guevara, Paulo Freire y la pedagogía de la revolución. Siglo XXI.

Mollis, M. (2011). La evaluación universitaria: entre una crisis de sentido y la respuesta social para el cambio. En A. Servetto y D. Saur (Comp.), Sentidos de la universidad (pp. 47-62). Universidad Nacional de Córdoba.

Mouffe, C. (1999). El retorno de lo político: Comunidad, ciudadanía, pluralismo, democracia radical. Paidós.

Mouffe, C. (2016). La paradoja democrática. Gedisa.

Müller, S. (1996). The advent of the university of calculation. En S. Müller (Ed.), Universities in the Twenty-First Century (pp. 15-23). Berghahn Books.

Oraisón, Mercedes. (2010). Individuación y participación: tensiones en la construcción de ciudadanía. En B. Toro y A. Tallone (Coord.), Educación, valores y ciudadanía (pp. 75-94). OEI.

Organización de las Naciones Unidas para la Educación, la Ciencia y la Cultura (1998). Declaración Mundial sobre la Educación Superior en el Siglo XXI: Visión y Acción. https://unesdoc.unesco.org/ search/N-EXPLORE-0be25aec-f586-447c-99a5-9e09c3b73613

Organización de las Naciones Unidas para la Educación, la Ciencia y la Cultura (2009). Conferencia Mundial sobre la Educación Superior 2009: La nueva dinámica de la educación superior y la investigación para el cambio social y el desarrollo. https://unesdoc.unesco.org/search/N-EXPLOREee19f05b-5b23-4162-a2b3-c7dd8e88e809

Organización de las Naciones Unidas para la Educación, la Ciencia y la Cultura, Instituto Internacional para la Educación Superior en América Latina y el Caribe (2018). Conferencia Regional de Educación Superior. https://es.unesco.org/events/iiia-conferencia-regional-educacion-superior-americalatina-y-caribe

Organización Internacional del Trabajo (2018). Perspectivas sociales y del empleo en el mundo: Tendencias 2018. https://www.ilo.org/global/research/global-reports/weso/2018/WCMS_631466/lang--es/index.htm

Puiggrós, A. (1996). Educación neoliberal y quiebre educativo. Nueva Sociedad, (54), 90-101. https:// nuso.org/autor/adriana-puiggros/

Rancière, J. (1996). El desacuerdo. Filosofía y política. Nueva Visión. 
Santos, B. (2003). La caída del Angelus Novus: ensayos para una nueva teoría social y una nueva práctica política. ILSA/Universidad Nacional de Colombia.

Santos, B. (2005). El milenio huérfano. Ensayos para una nueva cultura política. Trotta/ILSA.

Santos, B. (2015). La universidad en el siglo XXI. Siglo XXI.

Schmitt, C. (1998). El concepto de lo político. Alianza

Segato, R. y Álvarez, P. (2016). Frente al espejo de la reina mala. Docencia, amistad y autorización como brechas decoloniales en la universidad. Instituto Oscar Varsavsky. Cuadernos para el debate: Pensar la Universidad desde una crítica de la colonialidad, (2), 4-19. http://adiuc.org.ar/wp-content/ uploads/2019/02/cuaderno2-varsavsky.pdf

Sen, A. (2000). Desarrollo y libertad. Planeta.

Suasnabar, C. (2011). Tras las huellas de la idea de "Universidad Latinoamericana": una mirada histórica de la relación entre intelectuales, compromiso político y reflexión universitaria. En A. Servetto y D. Saur (Comp.), Sentidos de la universidad (pp. 137-162). Universidad Nacional de Córdoba.

Tünnermann, C. (1991). Historia de la Universidad en América Latina: De la época colonial a la Reforma de Córdoba. EDUCA

Vygotsky, L. (1985). Pensamiento y lenguaje. La Pléya.

Zibechi, R. (2003). Los movimientos sociales latinoamericanos: tendencias y desafíos. OSAL: Observatorio Social de América Latina, (9), 185-188. http://bibliotecavirtual.clacso.org.ar/ar/libros/osal/osal9/ zibechi.pdf 

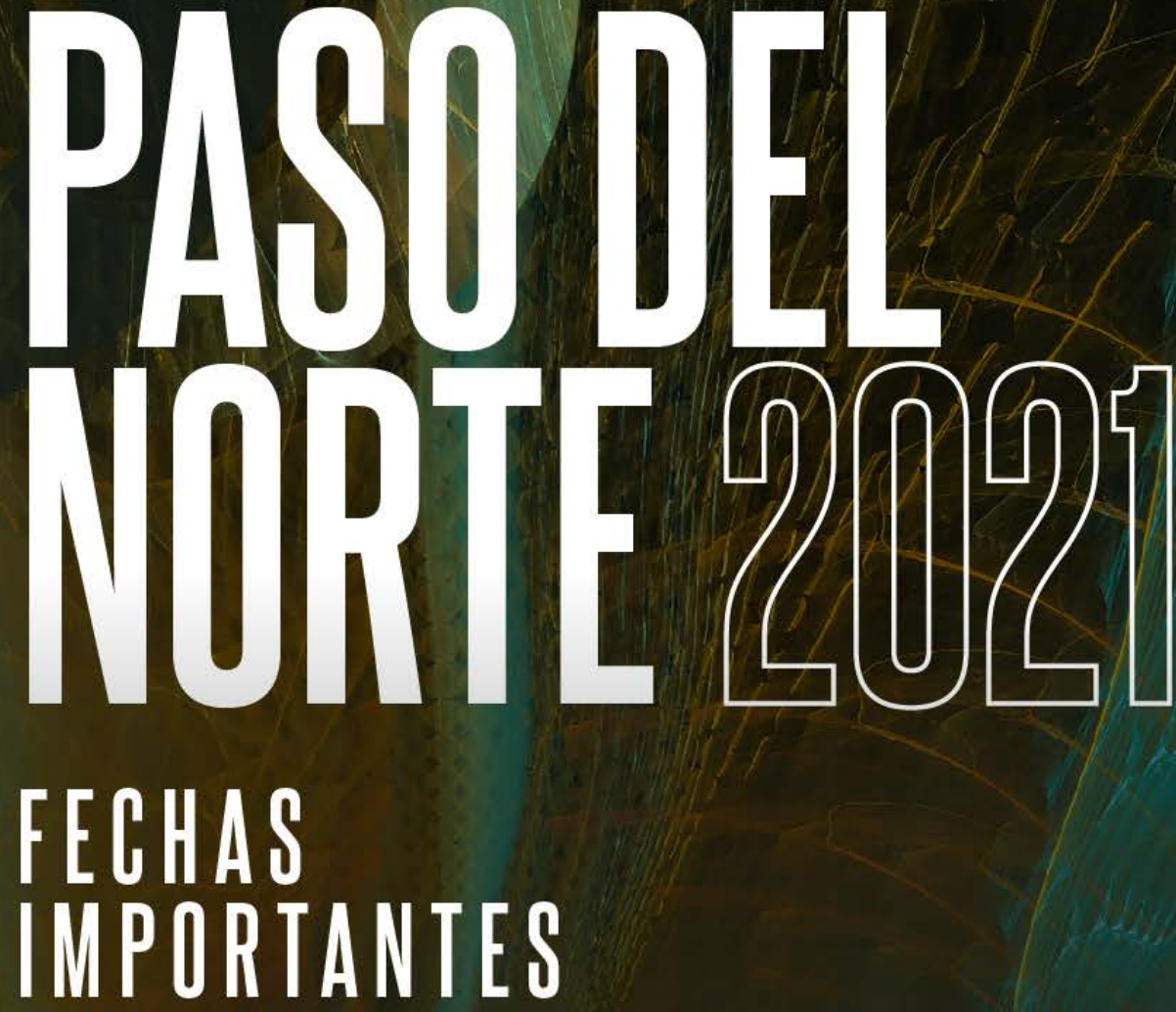

Recepción de trabajo

Del 15 de febrero al 7 de junio

Publicación de propuestas aceptadas 30 de julio

\begin{tabular}{ll}
\hline Fecha límite envío ponencias in extenso & $\mathbf{3 0}$ de septiembre \\
\hline Fecha límite de inscripción para ponentes & $\mathbf{8}$ de octubre \\
\hline Publicación del programa del Congreso & $\mathbf{2 2}$ de octubre \\
\hline Realización del Congreso & del $\mathbf{8}$ al $\mathbf{1 1}$ de noviembre \\
\hline Fecha límite para trámite de constancias & $\mathbf{3 0}$ de noviembre
\end{tabular}

Fecha límite para trámite de constancias

30 de noviembre

Registro de trabajos:

http://info.uacj.mx/congresocs2021 